\title{
Profil Hipertensi Di Poliklinik Penyakit Dalam RSUD Koja
}

\section{Hypertension Profile in Internal Medicine Polyclinic of RSUD Koja}

\author{
Suzanna Ndraha' ${ }^{1}$, Zulfikar Caesar ${ }^{2}$, Winda Afdilla ${ }^{2}$, \\ Wiwin Rianas ${ }^{2}$, Yurri Kamala², Zahra Farras², \\ Zegovine EF \\ 1Department of Internal Medicine, Koja Hospital, Jakarta \\ ${ }^{2}$ Faculty of Medicine, Universitas YARSI, Jakarta
}

KATA KUNCI

KEYWORDS

ABSTRAK
Hipertensi, Poliklinik Rawat Jalan, RSUD Koja

Hypertension, Internal Medicine, KojaHospital

Prevalensi hipertensi meningkat di seluruh dunia, terutama di negara-negara sedang berkembang. Kesadaran berobat dan pengendalian hipertensi lebih berhasil di Amerika Utara dibandingkan negara sedang berkembang dan negara miskin, termasuk Indonesia. Tujuan penelitian ini adalah untuk mendapatkan profil penderita hipertensi di rawat jalan Penyakit Dalam RSUD Koja.

Penelitian ini dilakukan dengan pendekatan deskriptif secara cross sectional. Populasi dari sampel adalah pasien poliklinik rawat jalan RSUD Koja yang didiagnosis hipertensi sepanjang bulan Oktober-Desember 2018.

Proporsi hipertensi di rawat jalan RSUD Koja didapatkan sebesar 36,2\% dari total 334 pasien. Jenis kelamin terbanyak adalah perempuan $(71,1 \%)$, rentang usia antara $21-87$ tahun, kelompok usia terbanyak 41-60 tahun, rerata tekanan darah sistolik (TDS) 153 (19.3) mmHg dan rerata tekanan darah diastolik (TDD) 84 (14.3) $\mathrm{mmHg}$, sebagian besar IMT normal, sebanyak $60 \%$ tidak rutin minum obat dan tekanan darahnya tidak mencapai target. Pasien hipertensi pada umumnya kurang patuh terhadap pengobatan karena ketidaktahuan mengenai cara mengkonsumsi obat. Banyak pasien (47\%) beranggapan bahwa apabila tekanan darah sudah stabil maka obat tidak perlu dikonsumsi lagi.

Proporsi hipertensi sebesar $36.2 \%$ dari total pasien rawat jalan, sebagian besar (60\%) tidak terkendali karena tidak rutin berobat dengan alasan terbanyak adalah karena ketidaktahuan $(47 \%)$. 
ABSTRACT Prevalence of hypertension is increasing worldwide, most prominently in low-income countries. Awareness, treatment, and control are most successful in North America while remaining a challenge in middle- and low-income countries, include Indonesia. Aim of this study is to find the profile of hypertension patients in Internal Medicine Clinic Koja General Hospital

This was a descriptive study with a cross sectional approach. Data was taken by consecutive sampling method from hypertension subjects who visited Department of Internal Medicine Clinic Koja General Hospital in the period of October to December, 2018

The proportion of hypertension subjects in Department of Internal Medicine Clinic Outpatients Koja General Hospital was $36.2 \%$. Gender was dominated by woman $(71,1 \%)$, age ranged from 21-87 years old, mostly in the group of 41-60 years old, the mean of systolic blood pressure (SBP) was 153 (19.3) $\mathrm{mmHg}$ and the mean of diastolic blood pressure (DBP) was 84 (14.3) $\mathrm{mmHg}$, mostly had normal BMI, 60\% had low awareness of medication and uncontrolled blood pressure. Poor compliance of taking antihypertensive medication occurred due to the lack of knowledge. Most of patients (47\%) speculated that no need any medication after reaching normal blood pressure. The proportion of hypertension subjects in Department of Internal Medicine Clinic Outpatients Koja General Hospital was $36.2 \%, 60 \%$ had low awareness and uncontrolled blood pressure, that occurred due to the lack of knowledge (47\%).

\section{PENDAHULUAN}

Prevalensi hipertensi meningkat di seluruh dunia, terutama di negaranegara sedang berkembang. Kesadaran berobat dan pengendalian hipertensi lebih berhasil di Amerika Utara dibandingkan negara sedang berkembang dan negara miskin. Kemudahan akses ke fasilitas kesehatan dan tatalaksana farmakologi adalah kunci sukses untuk menurunkan angka hipertensi di populasi (Cifkova $\mathrm{R}$ et al., 2016). Data di Amerika Serikat (20092010) menunjukkan prevalensi hipertensi sebesar 30.5\% (laki-laki) dan
$28.5 \%$ (perempuan). Pengendalian tekanan darah dicapai sebesar $40.3 \%$ (laki-laki) dan 56.3\% (perempuan) (Guo F et al., 2012). Sebuah metanalisis dari 16 penelitian di Afrika menyimpulkan adanya peningkatan prevalensi hipertensi yaitu dari $19.7 \%$ di tahun 1990, 27.4\% di tahun 2000 dan 30.8\% di tahun in 2010 (Adeloye D et al., 2014).

\footnotetext{
Correspondence:

Suzanna Ndraha, Department of Internal Medicine, Koja Hospital, Jakarta

Email:susaninternalmedicine@gmail.com
} 
Studi di China (2011-2012) yang melibatkan 13.583 responden dari 28 propinsi mendapatkan prevalensi hipertensi sebesar $41.7 \%$, sedangkan pengendalian tekanan darah hanya tercapai sebesar 23.4\% (Yin M et al., 2016). Sedangkan Kanada (2006) mencatat prevalensi yang lebih rendah yaitu $21.0 \%$, dengan pengendalian tekanan darah lebih tinggi yaitu $67.9 \%$ (Blais C et al., 2014). Di Indonesia, survey yang dilakukan tahun 1993-2008 mendapatkan prevalensi hipertensi sebesar 43.1\% (laki-laki) dan 52.3\% (perempuan). Pengendalian tekanan darah dicapai sebesar 27\% (laki-laki) dan $24.0 \%$ (perempuan) (Hussain MA et al., 2016). Penelitian ini bertujuan mendapatkan profil penderita hipertensi (gender, usia, indeks massa tubuh, rerata tekanan darah, pengendalian tekanan darah) di rawat jalan Penyakit Dalam RSUD Koja.

\section{METODE}

Disain studi yang digunakan pada penelitian ini adalah deskriptif kros-seksional. Penelitian ini dilakukan terhadap pasien rawat jalan di Poliklinik Penyakit Dalam RSUD Koja, Jakarta Utara dengan periode OktoberDesember 2018. Populasi subyek adalah pasien yang didiagnosis hipertensi berdasarkan kriteria JNC VII dan berobat ke poliklinik penyakit dalam. Pengambilan data dilakukan dengan cara wawancara dan diolah dengan menggunakan Microsoft Excel. Semua data numerik disajikan dalam mean (SD) sedangkan data kategorik disajikan dalam bentuk $\mathrm{n}(\%)$

\section{HASIL}

Telah dilakukan penelitian dalam kurun waktu Oktober-Desember 2018, didapatkan 121 orang (36,2\%) dari sebanyak 334 orang yang berkunjung ke poliklinik Penyakit Dalam RSUD Koja. Jenis kelamin terbanyak adalah Perempuan $(71,1 \%)$, rentang usia antara 21-87 tahun (tabel 1).

Tabel 1. Karakteristik pasien hipertensi $(n=121)$

\begin{tabular}{ll}
\hline Karakteristik & $\mathrm{n}(\%)$ \\
\hline Jenis Kelamin & \\
a. Laki-laki & $35(28,9)$ \\
b. Perempuan & $86(71,1)$ \\
Usia & \\
a. $18-25$ tahun & $2(1,6)$ \\
b. $26-40$ tahun & $9(7,4)$ \\
c. $41-60$ tahun & $65(53,7)$ \\
d. $>60$ tahun & $45(37,2)$ \\
Indeks massa tubuh (IMT) & \\
a. Kurus & $4(3.3)$ \\
b. Normal & $61(50,4)$ \\
c. Gemuk & $40(33,1)$ \\
d. Obes I & $14(11,6)$ \\
e. Obes II & $2(1.7)$ \\
\hline
\end{tabular}




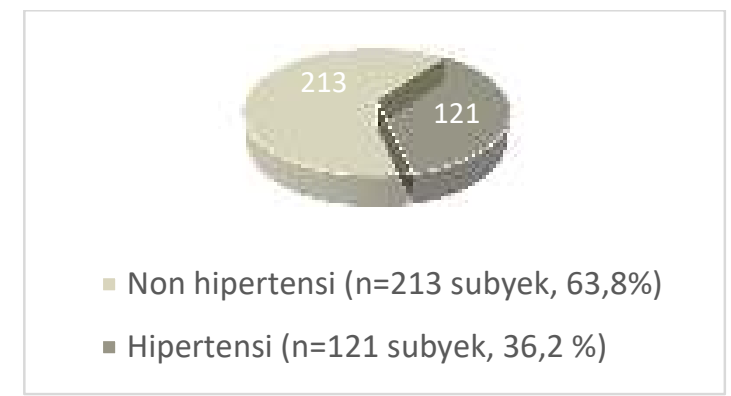

Gambar 1. Proporsi penderita hipertensi $(n=334)$

Pada Gambar 1 proporsi hipertensi yaitu $<140 / 90 \mathrm{mmHg}$, maka penderita hipertensi yang berkunjung ke poliklinik Penyakit Dalam RSUD Koja dalam kurun waktu 22 Oktober-15 Desember 2018 adalah sejumlah 121 orang $(36,2 \%)$ dari total seluruh pasien rawat jalan RSUD Koja sebanyak 334 orang. Sejumlah 121 subyek penderita hipertensi, didapatkan rerata tekanan darah sistolik (TDS) 153 (19.3) $\mathrm{mmHg}$ dan rerata tekanan darah diastolik (TDD) 84 (14.3) mmHg. Dengan mengacu kepada target pengendalian dari 121 subyek didapatkan 48 orang $(40 \%)$ yang mencapai target pengendalian dan rutin mengkonsumsi obat penurun tekanan darah. Sedang sisanya sejumlah 73 orang $(60 \%)$ tidak rutin minum obat dan tekanan darahnya tidak mencapai target (gambar 2). Kelompok dengan tekanan darah tidak terkendali, sebanyak 100\% menyatakan tidak rutin mengkonsumsi obat dengan alasan tidak mengkonsumsi Obat (Gambar 3).

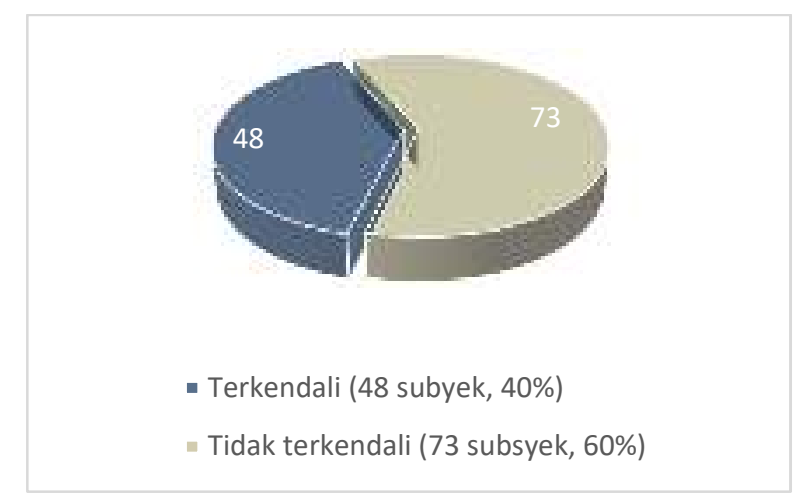

Gambar 2. Proporsi penderita tekanan darah terkendali $(\mathrm{n}=121)$

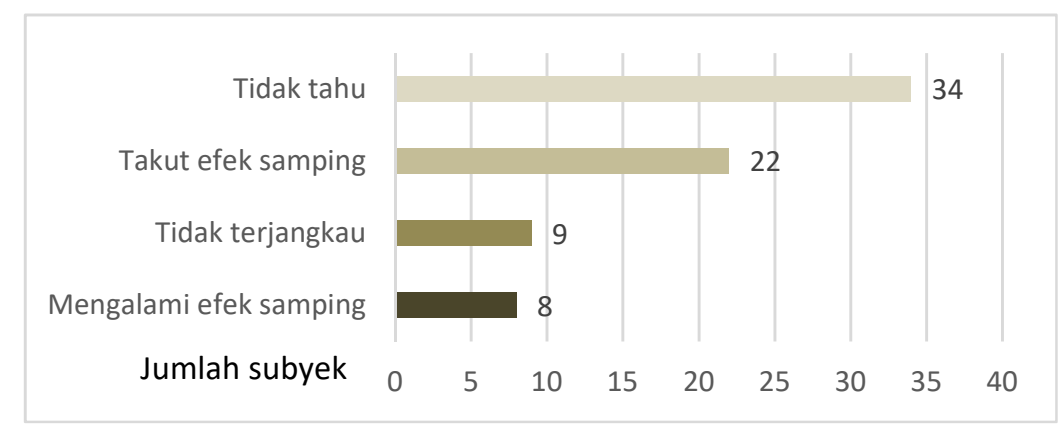

Gambar 3. Alasan tidak rutin mengkonsumsi obat $(n=73)$ 


\section{PEMBAHASAN}

Proporsi penderita hipertensi pada studi ini adalah $36,2 \%$. Angka ini lebih tinggi dibanding Kanada (21.0\%), juga lebih tinggi dari Amerika Serikat yang mencatat prevalensi hipertensi sebesar 30.5\% (laki-laki) dan 28.5\% (perempuan) (Blais C et al., 2014; Guo F et al., 2012). Angka ini juga lebih tinggi dari prevalensi hipertensi di negaranegara yang tergabung dalam The South Asian Association for Regional Cooperation (SAARC) yaitu India, Pakistan, Bangladesh, Nepal, Afghanistan, Sri Lanka, Bhutan, dan Maldives yang mencatat angka 27\% (Neupane D 2014). Namun dibanding data nasional di Indonesia yaitu sebesar 43.1\% (laki-laki) dan 52.3\% (perempuan), angka ini masih lebih rendah (Hussain MA et al., 2016). Perbedaan ini kemungkinan disebabkan karena prevalensi hipertensi memang lebih tinggi di negara sedang berkembang dibanding negara maju (Neupane D 2014). Kemungkinan lain karena perbedaan periode pengambilan data, dan perbedaan metoda penelitian.

Penelitian ini didapatkan bahwa pada populasi hipertensi, jumlah pasien perempuan lebih banyak dari laki-laki dengan rasio 3:1. Data ini tidak sejalan dengan data di Amerika Serikat (20092010) yang menunjukkan prevalensi hipertensi pada laki-laki hanya sedikit lebih besar dibanding perempuan (30.5\% vs 28.5\%) (Guo F et al., 2012). Proporsi penderita perempuan lebih banyak terlihat pada survey tingkat nasional di Indonesia, yaitu sebesar 43.1\% (laki-laki) dan 52.3\% (perempuan) namun perbandingannya tidak mencapai 1:3 (Adeloye D et al., 2014). Prevalensi hipertensi yang lebih tinggi pada laki-laki juga ditemukan oleh Neupane (2014) yang melakukan metanalisis terhadap 19 studi di Asia
Selatan, hanya 8 studi yang menyimpulkan prevalensi lebih tinggi pada perempuan. Kemungkinan penyebab perbedaan ini adalah besar sampel yang kecil pada penelitian ini.

Usia berpengaruh terhadap munculnya hipertensi. Pada penelitian ini, dapat terlihat bahwa kejadian hipertensi paling banyak pada kelompok usia 41-60 tahun (53.7\%), disusul kelompok usia $>60$ tahun (37.2\%). Hasil ini kurang sesuai dengan tulisan Rahajeng dan Tuminah (2009) yang menemukan bahwa pada lansia dibanding umur 55-59 tahun dengan umur 60-64 tahun terjadi peningkatan risiko hipertesi sebesar 2.18 kali, umur 65-69 tahun 2.45 kali dan umur $>70$ tahun 2.97 kali (Rahajeng dkk. 2009). Ketidaksesuaian ini kemungkinan karena kelompok usia >60 tahun di populasi kami tidak semuanya dapat mencapai sarana kesehatan untuk berobat.

Sebagian besar subyek mempunyai indeks massa tubuh (IMT) normal $(50.4 \%)$. Hal ini tidak sesuai dengan Cassani (2009) yang mendapatkan bahwa tingginya IMT, lingkar pinggang, dan tebal lipatan kulit menjadi salah satu faktor penting untuk memprediksi timbulnya hipertensi. Pada penelitian kami, umumnya penderita hipertensi mempunyai IMT normal karena pada dasarnya hipertensi merupakan penyakit multifaktorial sehingga IMT saja tidak dapat menjadi faktor risiko tunggal. Rerata tekanan darah sistolik (TDS) sebesar 153 (19.3) $\mathrm{mmHg}$ dan rata-rata tekanan darah diastolik (TDD) sebesar 84 (14.3) $\mathrm{mmHg}$. Dengan mengacu kepada target pengendalian hipertensi yaitu <140/90 mmHg, maka dari 121 subyek didapatkan 48 orang $(40 \%)$ yang mencapai target pengendalian dan rutin 
mengkonsumsi obat penurun tekanan darah. Angka ini tidak jauh berbeda dengan angka pengendalian tekanan darah di Amerika Serikat yaitu sebesar 40.3\% (laki-laki) dan 56.3\% (perempuan) (Guo F et al., 2012). Angka ini lebih tinggi dari pengendalian tekanan darah tingkat nasional yaitu sebesar $27 \%$ (lakilaki) dan $24.0 \%$ (perempuan) (Hussain MA et al., 2016). Walau angka pengendalian tekanan darah ini relatif lebih tinggi dari angka rata-rata di Indonesia, namun secara absolut kelompok yang mencapai target masih kurang dari $50 \%$.

Dari data ini dapat dilihat bahwa pasien hipertensi pada umumnya kurang patuh terhadap pengobatan karena masih banyak pasien yang salah persepsi mengenai cara mengkonsumsi obat. Pasien beranggapan bahwa apabila tekanan darah sudah stabil maka obat tidak perlu dikonsumsi lagi $(47 \%)$. Alasan kedua adalah pasien kuatir akan efek samping obat yang diminum jangka panjang (30\%). Alasan selanjutnya adalah sebagian subyek kesulitan untuk mendatangi klinik Penyakit Dalam RSUD Koja secara rutin karena tidak ada keluarga yang mengantar $(12 \%)$, dan sisanya karena pernah mengalami efek samping obat seperti batuk dan edema tungkai (11\%). Semua alasan diatas adalah penyebab ketidak patuhan berobat. Ketidakpatuhan memang merupakan masalah umum bagi penderita hipertensi. Pasien hipertensi cenderung mengalami kesulitan mempertahankan kebiasaan meminum obat rutin dikarenakan jumlah obat yang banyak serta frekuensi terlalu sering sehingga membingungkan pasien dan membuat pasien lupa (Vrijens B et al., 2017).

\section{KESIMPULAN}

Hasil penelitian ini menunjukan jumlah profil penderita hipertensi pada poliklinik Penyakit Dalam RSUD Koja adalah proporsi hipertensi sebesar $36.2 \%$ dari total pasien rawat jalan, gender perempuan sedikit lebih banyak, kelompok usia terbanyak 41 - 60 tahun, sebagian besar IMT normal, sebagian besar $(60 \%)$ tidak terkendali karena tidak rutin berobat dengan alasan terbanyak adalah karena ketidaktahuan (47\%).

\section{KEPUSTAKAAN}

Adeloye D, Basquill C 2014. Estimating the Prevalence and Awareness Rates of Hypertension in Africa: A Systematic Analysis. PLoS One; San Francisco 2014; 9(8): e104300.

Blais C, Rochette L, Hamel D, Poirier P 2014. Prevalence, incidence, awareness and control of hypertension in the province of Quebec: Perspective from administrative and survey data. Can J Public Health 2014;105(1):e79-e85.

Cassani RSL, Nobre F, Pazin-Filho A, Schmidt A 2009. Relationship between blood pressure and anthropometry in a cohort of Brazilian men: A crosssectional study. Am J Hypertens. 2009;22(9):980-4.

Cifkova R, Fodor G, Wohlfahrt P 2016. Changes in Hypertension Prevalence, Awareness, Treatment, and Control in High-, Middle-, and Low-Income Countries: An Update. Curr Hypertens Rep 2016; 18(8): 1-6.

Guo F, He D, Zhang W, Walton RG 2012. Trends in Prevalence, Awareness, Management, and Control of Hypertension Among United States Adults, 1999 to 2010. Journal of the American College of Cardiology 2012; 60(7): 599-606. 
Hussain MA, Al Mamun A, Reid C, Huxley RR 2016. Prevalence, Awareness, Treatment and Control of Hypertension in Indonesian Adults Aged $\geq 40$ Years: Findings from the Indonesia Family Life Survey (IFLS). PLoS One; San Francisco 2016; 11(8): e0160922.

Neupane D, etc 2014. Prevalence of Hypertension in Member Countries of South Asian Association for Regional Cooperatio (SAARC) Systematic Review AND Meta-Analysis.Medicine (Baltimore); WHO 2014 Sep;93(13) e74.

Rahajeng E, Tuminah S 2009. Prevalensi Hipertensi dan Determinannya di
Indonesia. Majalah Kedokteran Indonesia. 2009. 59(12):580-587.

Vrijens B, Antoniou S, Burnier M, Sierra A, Volpe M 2017. Current Situation of Medication Adherence in Hypertension. Frontiers in Pharmacology 2017; 8: 100.

Yin M, Augustin B, Fu Z, Yan M, Adan Fu A, Yin P 2016. Geographic Distributions in Hypertension Diagnosis, Measurement, Prevalence, Awareness, Treatment and Control Rates among Middle-aged and Older Adults in China. Scientific Reports (Nature Publisher Group); London 2016;6: 1-11 